\title{
Chemical gastritis after chronic bromazepam intake: a case report
}

Oliver Kirschberg ${ }^{1 *}$, Thomas Saers ${ }^{1}$, Bernd Krakamp ${ }^{1}$, Michael Brockmann ${ }^{2}$

\begin{abstract}
Background: We describe a rare case of diffuse macroscopic discoloration and chemical gastritis due to chronic bromazepam intake. The chemical composition of pharmaceuticals has to be considered at endoscopy and it is evident that some chemical substances damage the epithelial tissue and lead to clinical symptoms.

Case Presentation: Endoscopy was performed in an 82-year-old patient due to gastroesophageal reflux symptoms and epigastric pain. Gastroscopy showed a hiatal hernia and a scarred duodenal bulb. More striking was the yellow-brownish discoloration of the gastric and the duodenal mucosa. The gastric antrum and the duodenal bulb showed local discoloration that could not be rinsed off. The medical history indicated that bromazepam (6 mg) had been used daily as a sleeping aid in the previous two years. The histopathological findings showed appearances of chemical gastritis. Within the lamina propria and on the epithelial surface there were granules. There was no foreign body reaction to these granules. Corpus mucosa showed a mild chronic gastritis.

Conclusions: If discoloration of the mucosa at endoscopy is seen, a careful drug history must be sought. This is the first case in literature that shows a chemical gastritis after bromazepam intake.
\end{abstract}

\section{Background}

We describe a rare case of diffuse macroscopic discoloration and chemical gastritis due to chronic bromazepam intake. The chemical composition of pharmaceuticals has to be considered at endoscopy and it is evident that some chemical substances damage the epithelial tissue and lead to clinical symptoms.

\section{Case Presentation}

Endoscopy was performed in an 82-year-old patient due to gastroesophageal reflux symptoms and epigastric pain. Gastroscopy showed hiatal hernia and a scarred duodenal bulb.

More striking was the yellow-brownish discoloration of the gastric and duodenal mucosa. The gastric antrum and the duodenal bulb showed local discoloration that could not be rinsed off (Figures 1 and 2). The medical history indicated that bromazepam $(6 \mathrm{mg})$ had been used daily as a sleeping aid in the previous two years.

The histopathologic findings of the gastric antrum showed foveolar hyperplasia, smooth muscle

\footnotetext{
* Correspondence: kirschbergo@kliniken-koeln.de

'Department of Internal Medicine II, University of Witten/Herdecke, Campus Cologne-Merheim, Ostmerheimerstrasse 200, D-51109 Cologne, Germany
}

proliferation and a scant chronic inflammatory infiltrate with dilated vessels, appearances of chemical gastritis. Within the lamina propria and on the epithelial surface there were granules (Figure 3). There was no foreign body reaction to these granules. Corpus mucosa showed a mild chronic gastritis.

\section{Conclusions}

This is an uncommon example for discoloration of the epithelial surface in the stomach, especially the gastric antrum and the duodenal bulb (Figures 1 and 2). In the literature, only a few examples of discoloration of the gastric mucosa or epithelial surface can be found. In one case Chung et al. [1] found an infectious disease related to a green discoloration in the stomach. Several other reports refer to esophageal injuries after medication intake. Iron tablets [2], doxycycline [3], cyproterone acetate and ethinylestradiol [4] are all described to have led to painful esophagitis. Even a presentation of esophageal cancer-like symptoms after doxycycline intake is described by Tahan et al. [5]. There is little information regarding discoloration of the gastric antrum and duodenal bulb, despite their known propensity to be a hot spot for bleedings, ulcerations, and tumors. 


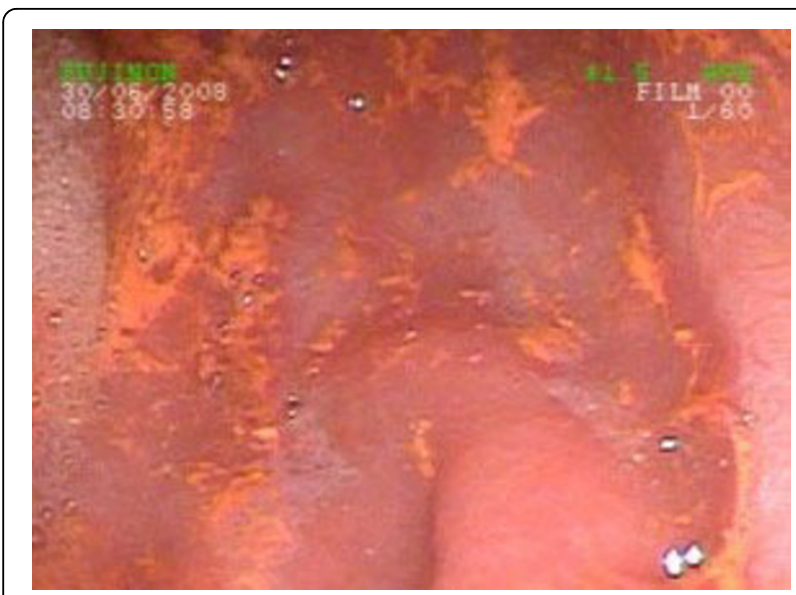

Figure 1 Endoscopy appearance of the gastric antrum with discoloration after bromazepam intake.

In addition to the macroscopic findings some granules are found microscopically in the mucous that could not be rinsed away (Figure 3). The etiology for this histological finding is not clear. It could be assumed that bromazepam is able to interact with the epithelial surface in an acid milieu. The active pharmaceutical ingredient is bromazepam $\left[\left(\mathrm{C}_{14} \mathrm{H}_{10} \mathrm{BrN}_{3} \mathrm{O}\right)\right.$, (Figure 4)] containing a bromo substituent. Elemental bromine is a reactive element. Reactivity is based on its ability to react with certain metals to generate salts. The color of elemental

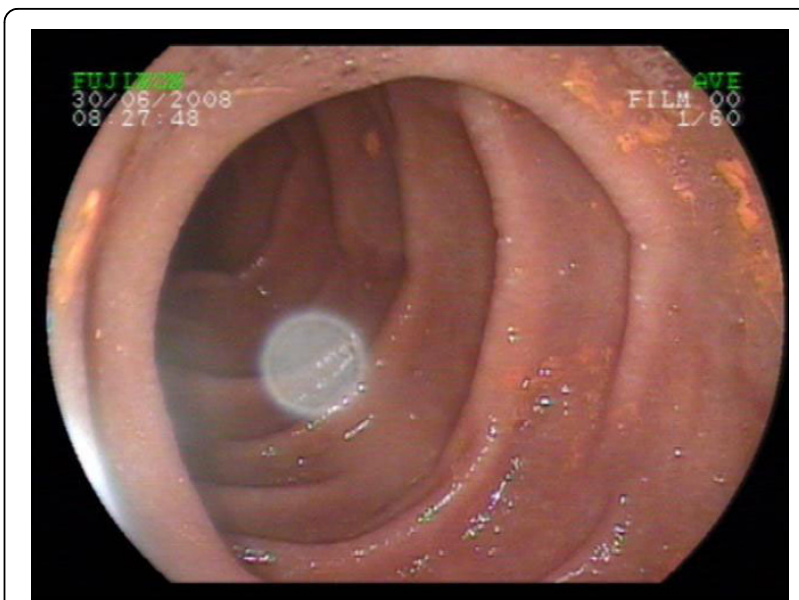

Figure 2 Discoloration of the duodenal bulb after bromazepam intake.

bromine appears in the liquid or gas phase reddishbrown. Yet, any generated bromine in tissue would only be transient, because of its reactive nature. In general medical practice bromine derivatives are used as disinfectants. Bromine is also encountered as a moiety in certain CNS-active drugs (Table 1) [CNS - central nervous system].

Iodine, as an example for the same chemical group, is used for coloration of squamous epithelium in the esophagus by absorption in the epithelial cells $[6,7]$. This

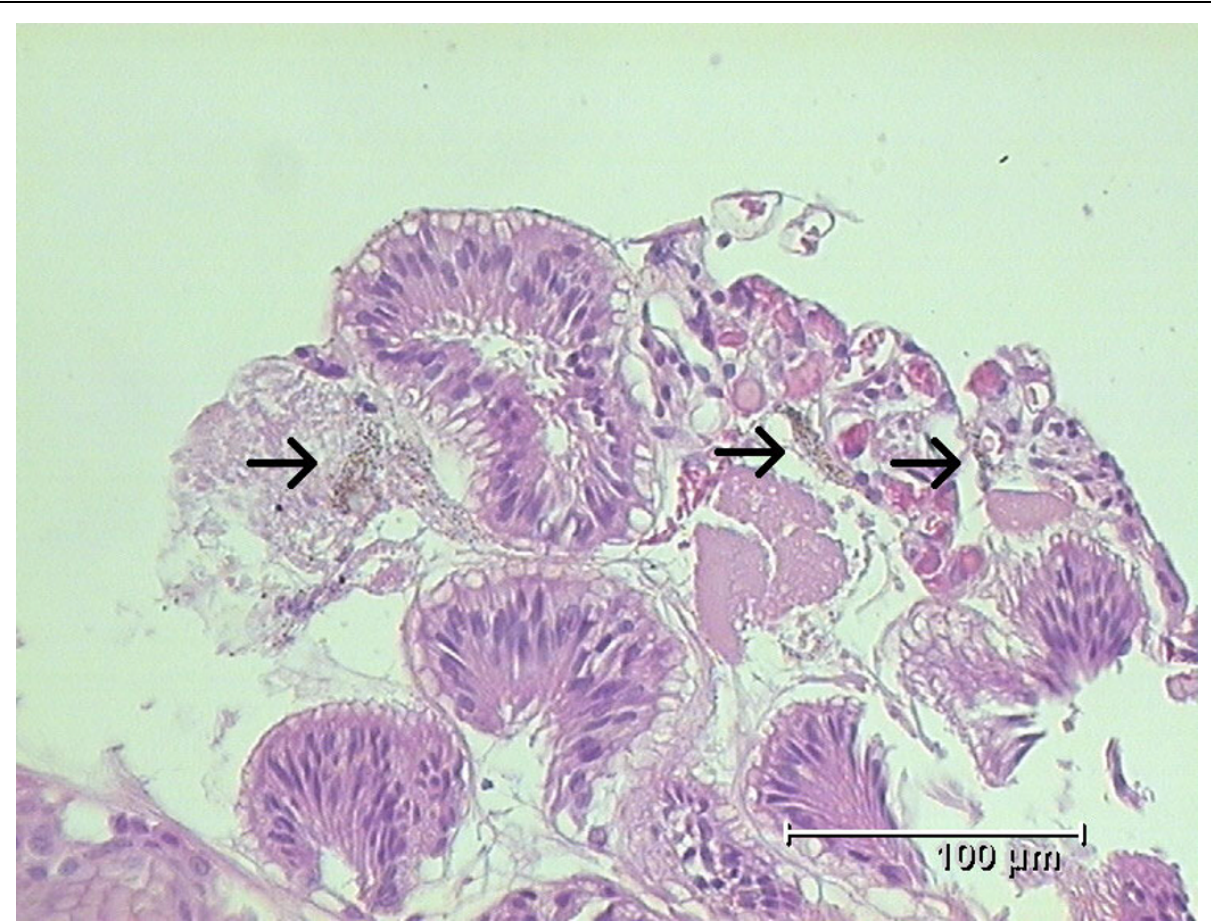

Figure 3 Histology of gastric antral mucosa. Arrows show the granules embedded in the mucus and the epithelial surface. 
Table 1 Drugs containing bromine (selection):

\begin{tabular}{ll}
\hline Medical drugs: & \\
\hline pulmonary drugs & bromhexin hydrochloride $8 \mathrm{mg} / 5 \mathrm{ml}$ \\
\hline psychotropic drugs or CNS drugs & bromocriptin mesilat $5.735 \mathrm{mg} / \mathrm{pill}$ \\
& $\begin{array}{l}\text { bromazepam } 6 \mathrm{mg} / \text { pill } \\
\text { bromperidol lactate } 5 \mathrm{mg} / \text { pill }\end{array}$ \\
\hline
\end{tabular}

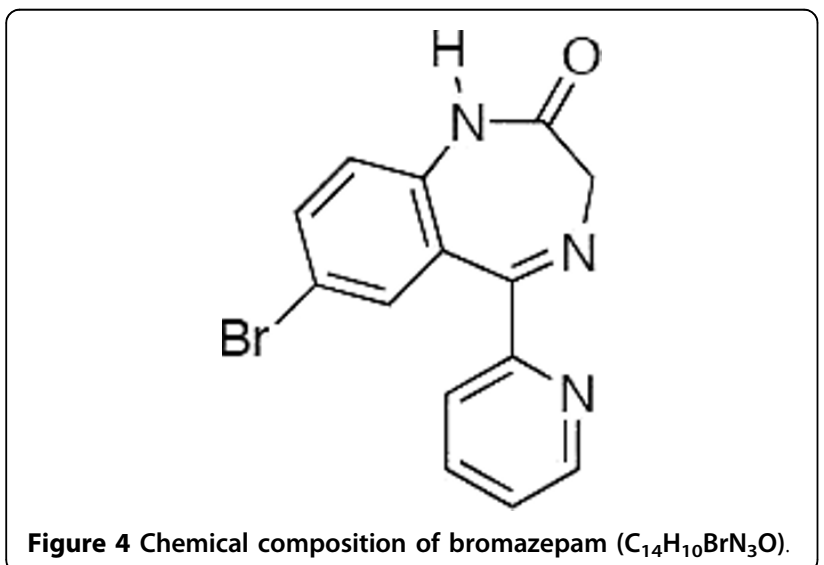

discoloration penetrats the mucosa. Thuler et al. describes a chemical esophagitis after using Lugol's solution for detecting esophageal cancer [8]. In contrast to these findings in use of iodine, the bromazepam discoloration refers only to the epithelial surface and the mucus.

This may be a reason for clinical symptoms like epigastric pain. As far as the literature is concerned this is the first case where bromazepam is able to discolor epithelial tissue in specific parts of the stomach.

\section{Consent}

Written informed consent was obtained from the patient for publication of this case report and accompanying images. A copy of the written consent is available for review by the Editor-in-Chief of this journal.

\section{Acknowledgements}

Special acknowledge to T. A. Kirschberg, Ph.D, for proofreading the manuscript and illustrating the chemical composition of bromazepam.

\section{Author details}

${ }^{1}$ Department of Internal Medicine II, University of Witten/Herdecke, Campus Cologne-Merheim, Ostmerheimerstrasse 200, D-51109 Cologne, Germany.

${ }^{2}$ Department of Pathology, Cologne-Merheim Medical Center (CMMC), Ostmerheimerstrasse 200, D-51109 Cologne, Germany.

\section{Authors' contributions}

OK and BK prepared case report. OK and TS analyzed case report and performed literature research. MB analyzed the specimen and took microscopic photos. All authors read and reviewed the final manuscript.

\section{Competing interests}

The authors declare that they have no competing interests.
Received: 24 February 2010 Accepted: 29 July 2010

Published: 29 July 2010

\section{References}

1. Chung CS, Wang WL, Liu KL, Lin JT, Wang HP: Green ulcer in the stomach: unusual mucormycosis infection. Gastrointest Endosc 2008, 68(3):566-7, discussion567. Epub 2008 Jun 17.

2. Cerezo A, Costan G, Gonzale A, Galvez C, Garcia V, Iglesias E, Reye A, DE Dios JF: Severe esophagitis due to overdose of iron tablets. Gastroenterol Hepatol 2008, 31(8):511-2.

3. Delpre $G$, Kadish $U$, Stahl B: Induction of esophageal injuries by doxycycline and other pills. A frequent but preventable occurrence. Dig Dis Sci 1989, 24(5):797-800.

4. Gulsen MT, Buyukberber NM, Karaca M, Kadayifci A: Cyproterone acetate and ethinylestradiol-induced pill oesophagitis: a case report. Int J Clin Pract Suppl 2005, , 147: 79-81.

5. Tahan V, Sayrak H, Bayar N, Erer B, Tahan G, Dane F: Doxycycline-induced ulceration mimicking esophageal cancer. Cases J 2008, 1(1):144.

6. Qureshi S, Das V, Zahra F: Evaluation of visual inspection with acetic acid and Lugol's iodine as cervical cancer screening tools in a low-resource setting. Trop Doct 2009.

7. Maeda K, Suzuki T, Ooyama Y, Nakakuki K, Yamashiro M, Okada N, Amagasa T: Colorimetric analysis of unstained lesions surrounding oral squamous cell carcinomas and oral potentially malignant disorders using iodine. Int J Oral Maxillofac Surg 2009.

8. Thuler FP, de Paulo GA, Ferrari AP: Chemical esophagitis after chromoendoscopy with Lugol's solution for esophageal cancer: case report. Gastrointest Endosc 2004, 59(7):925-6.

\section{Pre-publication history}

The pre-publication history for this paper can be accessed here: http://www.biomedcentral.com/1471-230X/10/84/prepub

\section{doi:10.1186/1471-230X-10-84}

Cite this article as: Kirschberg et al:: Chemical gastritis after chronic bromazepam intake: a case report. BMC Gastroenterology 2010 10:84.

\section{Submit your next manuscript to BioMed Central and take full advantage of:}

- Convenient online submission

- Thorough peer review

- No space constraints or color figure charges

- Immediate publication on acceptance

- Inclusion in PubMed, CAS, Scopus and Google Scholar

- Research which is freely available for redistribution 